\title{
Incidence, predictors of success and outcome of LISA in very preterm infants
}

\author{
Gergely Balázs ${ }^{1}$, Andras Balajthy ${ }^{1}$, Magdolna Riszter ${ }^{1}$, Tamas Szabo ${ }^{1}$, Tamas Kovacs ${ }^{1}$, \\ Gusztav Belteki ${ }^{2}$, and Gyorgy Balla ${ }^{1}$ \\ ${ }^{1}$ University of Debrecen Clinical Centre \\ ${ }^{2}$ Cambridge University Hospitals NHS Foundation Trust
}

September 25, 2021

\begin{abstract}
Objectives: To examine the success rate of less invasive surfactant administration (LISA), to identify early predictive factors for the outcome of LISA and to compare neonatal outcomes between the LISA failure group and the group of infants who were succesfully treated with LISA. Design: A retrospective cohort study. Patients: Infants born at less than 33 weeks of gestation $(\mathrm{n}=158)$ and treated with LISA for respiratory distress syndrome. Results: LISA was successful in 86 cases (54.4\%), 72 preterm infants $(45.6 \%)$ needed additional surfactant therapy and/or mechanical ventilation in the first 72 hours. In a multivariate logistic regression analysis, six independent predictors were identified: core temperature at the time of admission (adjusted OR 3.56), suboptimal dose of surfactant (adjusted OR 0.254), elevated CRP (>10 mg/L) at 24 hours of life (adjusted OR 0.28), highest respiratory severity score during the first hour of life or at the time of LISA (adjusted OR 0.463), maternal age (adjusted OR 0.923) and birth weight (adjusted OR 1.003). The ROC curve created by using the identified factors indicates good predictive power with an area under the curve of 0.85 . LISA failure was associated with a substantially higher risk of pneumothorax, bronchopulmonary dysplasia, intraventricular hemorrhage, severe retinopathy of prematurity, longer duration of mechanical ventilation and prolonged length of hospital stay. Conclusion: Failure of LISA is relatively frequent event in very preterm infants and is associated with adverse outcomes. Prevention of hypothermia during early stabilization and appropriate dosing of surfactant increase may LISA success rates and improve patient outcome.
\end{abstract}

\section{Introduction}

Respiratory distress syndrome (RDS), a condition caused by lung immaturity and surfactant deficiency, is one of the most prevalent complications associated with prematurity ${ }^{1}$. The potential harmful effects of mechanical ventilation on preterm infants are well known ${ }^{2}$. Even a short period of positive pressure ventilation can initiate an inflammatory cascade leading to bronchopulmonary dysplasia (BPD $)^{3}$, while avoiding intubation improves neonatal outcomes ${ }^{4,5}$. Continuous positive airway pressure (CPAP) is a widely used mode of respiratory support in preterm infants with $\mathrm{RDS}^{6,7}$. However, CPAP fails to provide sufficient support in 40-65\% of preterm infants. These patients require endotracheal intubation followed by mechanical ventilation, which is associated with significant risk of complications and long term morbidities ${ }^{8-10}$. In 1992, a thin catheter method (less invasive surfactant administration - LISA) was described for the first time ${ }^{11}$, and was rediscovered a decade later by Kribs et al. ${ }^{12}$. During LISA, a thin catheter is passed through the vocal cords into the trachea for surfactant administration, while noninvasive ventilatory support is continued without interruption, and the infant can breathe spontaneously ${ }^{13}$. Initial randomized controlled trials concluded that LISA is a feasible alternative to surfactant administration ${ }^{14-16}$. LISA has been shown to reduce the need for mechanical ventilation, even though the individual studies have not demonstrated any statistical difference in the composite outcome of death and BPD when comparing LISA to nasal CPAP alone, intubation-surfactant-extubation (INSURE) technique and mechanical ventilation ${ }^{15,17}$. Recent systematic 
reviews and metaanalyses point out that LISA is superior to other modes of surfactant delivery in the reduction of $\mathrm{BPD}$ and intraventricular haemorrhage $(\mathrm{IVH})^{18-22}$. These findings have led to the European Consensus Guidelines on the Management of Respiratory Distress Syndrome recommendation that LISA is a worthy alternative to surfactant administration even in extremely low birth weight neonates, and should be the preferred mode of surfactant delivery for spontaneously breathing preterm infants on $\mathrm{CPAP}^{7}$. $\mathrm{A}$ two-year follow-up of the first randomized study with LISA raised no safety concerns over weight, length and neurodevelopmental outcome in comparison to standard care (optional rescue surfactant replacement with endotracheal intubation followed by mechanical ventilation $)^{23}$. Although the introduction of small-diameter catheter techniques has increased the success rate of early prophylactic CPAP, a significant proportion of preterm infants ultimately fails on CPAP and requires invasive ventilation ${ }^{12,14,24}$.

\section{Methods}

\section{Study group}

This single-center retrospective study was conducted between 1 January 2014 and 31 December 2019 in the Division of Neonatology of the Department of Pediatrics of the University of Debrecen. Inborn preterm infants born before 33 completed weeks of gestation, and stabilized on CPAP in the delivery room, then treated with LISA, were included in the study. Preterm infants requiring intubation during delivery room stabilization or immediately after admission to NICU, and those born with any congenital anomaly were excluded from the study.

\section{Delivery room care}

Mothers at risk of preterm delivery received antenatal steroid (ANS) prophylaxis (32mg dexamethasone in divided doses) and magnesium sulphate for neonatal neuroprotection. A single repeat dose of dexamethasone was given when ANS prophylaxis was administered $>2$ weeks prior to delivery. Cord clamping was delayed by 30 to 60 seconds, and umbilical cord milking was performed in emergency situations only. Delivery room (DR) stabilization of infants born at [?]32 weeks of gestation was started with early prophylactic CPAP using a T-piece ventilator with a face mask (Neopuff ${ }^{\mathrm{TM}}$, Fisher \& Paykel, Auckland, New Zealand), with a CPAP pressure of 6-9 $\mathrm{cmH}_{2} \mathrm{O}$ and a fraction of inspired oxygen $\left(\mathrm{FiO}_{2}\right)$ of 0.3 for infants $<28$ weeks, 0.21-0.3 for patients between 28 and 31 weeks, and 0.21 for infants born at 32 weeks and above. FiO 2 was titrated to meet age-specific target oxygen saturation $\left(\mathrm{SpO}_{2}\right)$ values, guided by pulse oximetry (GE Dash 3000 Patient Monitor, GE Healthcare, Chicago, United States, or Masimo Root Monitor with Radical 7 Handheld Pulse Oximeter, Masimo Corporation, Irvine United Stated). Tactile stimulation was performed to enhance spontaneous breathing. Positive pressure ventilation (PPV) with $20-25 \mathrm{cmH}_{2} \mathrm{O}$ peak inspiratory pressure was used in infants with persistent apnoe and/or bradycardia. Sustained inflations were not performed, and endotracheal intubation was reserved for babies not responding to positive pressure ventilation with supplemental oxygen.

After admission to the neonatal intensive care unit (NICU), infants received nasal CPAP using a Dräger Babylog VN500 ventilator (Dräger Medical, Lübeck, Germany), or Infant Flow system (Care Fusion, Dublin, Ohio, USA). Infants also received ampicillin plus gentamicin which were stopped at 48 hours in the absence of signs and symptoms of sepsis, with C-reactive protein $<10 \mathrm{mg} / \mathrm{L}$, and negative blood culture. During oxygen supplementation, $\mathrm{FiO}_{2}$ and CPAP levels were titrated to meet the target $\mathrm{SpO}_{2}$ range of 90-95\%. A $20 \mathrm{mg} / \mathrm{kg}$ loading dose of caffeine-citrate followed by $5 \mathrm{mg} / \mathrm{kg} /$ day maintenance doses was given before the surfactant treatment.

\section{LISA}

Before September 2017, exogenous surfactant (poractant alfa, Curosurf, Chiesi Pharmaceuticals, Parma, Italy) was indicated in accordance with the actual European Consensus Guidelines on the Management of Respiratory Distress Syndrome, after this date, surfactant replacement was indicated if $\mathrm{FiO}_{2}$ requirement exceeded 0.3 and/or the Silverman-Anderson score was [?]5 in all preterm infants ${ }^{25-27}$. The recommended dose was $200 \mathrm{mg} / \mathrm{kg}$, but dose rounding occured occasionally as per institutional protocol to reduce waste 
and health care costs. LISA was the preferred method in spontaneously breathing preterm infants; however, based on the clinical condition of the infant, the attending neonatologist could choose the option of intubation for surfactant therapy. LISA was contraindicated in infants with hemodynamic instability, severe $\mathrm{RDS}\left(\mathrm{FiO}_{2}>0.6\right.$ and/or $\mathrm{pH}<7.2$, and/or prominent atelectasis on chest X-ray), recurrent apneas despite caffeine loading, known air leaks, maxillofacial, airway or pulmonary malformations, and possible lung hypoplasia. Nonpharmacologic measures (e.g. swaddling, administration of colostrum) were encouraged to enhance comfort, and no premedication was given routinely before LISA. Nasal CPAP was continued during the whole procedure. Before laryngoscopy an orogastric/nasogastric tube was inserted to help the identification of anatomical structures and for intermittent gastric aspiration aimed to assess potential surfactant misplacement. LISA was performed by the attending neonatologist in all cases. A $5 \mathrm{Ch}$, gamma-sterilized, flexible feeding tube (Sumi, Sulejowek, Poland) was placed 1.5-2.0 cm below the vocal cords by direct laryngoscopy with or without Magill's forceps, the laryngoscope was removed, the mouth was kept closed, and surfactant was instilled in small $(0.2-0.4 \mathrm{~mL})$ aliquots over 2-3 minutes. If $\mathrm{FiO}_{2}$ exceeded 0.4 and/or the Silverman-Anderson score remained $>5$, and other causes of respiratory failure had been excluded, a second or third dose of surfactant was given using LISA during the first 72 hours of life. The criteria for mechanical ventilation were the following: $\mathrm{FiO}_{2}[?] 0.5, \mathrm{pH}<7.2, \mathrm{pCO}_{2}>60$ torr $(8 \mathrm{kPa}$ ), frequent episodes of apnea requiring stimulation, or 2 episodes of apnea unresponsive to stimulation or requiring PPV within 12 hours.

\section{Data collection}

Our main aim was to examine the success rate of LISA (LISA-S; defined as no need for additional surfactant treatment and/or mechanical ventilation within 72 hours after the first LISA), and to identify early predictive factors for the outcome of LISA. We also compared neonatal outcomes between the groups of infants who succeeded on nasal CPAP after the first LISA and the LISA failure group (LISA-F).

Data were collected from both written and electronic neonatal and maternal medical records. The study was approved by the Regional and Institutional Research Ethics Committee of the University of Debrecen. Maternal, perinatal and neonatal data are listed in table 1. Besides mortality, further outcome indices included the incidence of tension pneumothorax, BPD and severe $\mathrm{BPD}^{28}$, the need for postnatal steroid treatment for $\mathrm{BPD}^{29}$, intraventricular hemorrhage (IVH) and severe $\mathrm{IVH}^{30}$, periventricular leukomalacia $(\mathrm{PVL})^{31}$, retinopathy of prematurity (ROP) and severe $\mathrm{ROP}^{32}$, and necrotizing enterocolitis (NEC) requiring laparotomy. Based on clinical data, we studied the composite outcome of "death or major morbidity" (defined as death or at least one of the following morbidities: severe BPD, severe IVH, severe ROP, NEC, PVL), and survival without major morbidity; also, we collected data on duration of mechanical ventilation, the need for high-frequency oscillatory ventillation (HFO) ventilation and time to discharge to home.

The study was approved by the Scientific and Research Ethics Committee of the University of Debrecen under the registration number of „DE RKEB/IKEB 5616-2020”, and was conducted in accordance with the ethical standards of all relevant national and institutional committees and the World Medical Association's Declaration of Helsinki.

\section{Statistical analysis}

Numeric variables were compared using unpaired Student's T-test or one-way analysis of variance (ANOVA). In case of categorical variables, we performed Pearson-Chi-square or Fisher's exact test. To identify the predictors for LISA-S, first we performed univariate regression analysis on all the potential risk factors (Table 1). For multivariate forward stepwise logistic regression model we used the variables with a p value lower than 0.1 at univariate level. Co-linearity was analyzed using the Pearson's correlation coefficient; if $\mathrm{r}$ value was $>0.6$, one of the indicated variables was excluded from the regression model. We calculated the crude odds ratios (OR) at univariate level, and adjusted OR values at multivariate level with $95 \%$ confidence interval (CI) to demonstrate the differences in regression analysis. Data analysis was performed using the SPSS V.25 program. Statistical significance was accepted when two-sided p was $<0.05$.

\section{Results}


During the study period 569 preterm infants were born at less than 33 weeks of gestational age, of whom 158 underwent LISA procedure (Image 1 ). Descriptive statistics of the preterm infants included in the study is summarized in Table 2. The respiratory outcome of the study population is presented in Image 1. Mechanical ventilation was completely avoided in 104 cases $(65.8 \%)$, and endotracheal intubation was necessary in 54 cases (CPAP failure, CPAP-F) in the first 72 hours. Image 2 demonstrates that success rate of LISA increases with increasing gestational age, and the rate of CPAP-F cases gradually decreases (except for the subgroup of infants born at 26 weeks of gestation). Compared the LISA-F group to the preterm infants treated successfully with LISA (LISA-S), those with LISA-F had been born at a younger gestational age $(28.6$ weeks vs. 27.1 weeks, $\mathrm{p}<0.001)$, with lower birth weight (1134 grams vs. 895.56 grams, $\mathrm{p}<0.001$ ), in worse general condition (1-minute Apgar score of 6.78 vs. $6.28, \mathrm{p}=0.03$ ) and with lower admission temperature $\left(36.24{ }^{\circ} \mathrm{C}\right.$ vs. $\left.35.88^{\circ} \mathrm{C}, \mathrm{p}<0.001\right)$. We found no significant difference in the rest of the examined pre- and postnatal risk factors between the LISA-S and LISA-F group (Table 3 ).

In Table 1, we listed all the potential predictive factors for LISA-S. Multiple variables showed significant difference in univariate analysis but after co-linearity examinations only 9 remained for further calculations. In the multivariate logistic regression model, we could identify 6 independent risk factors that predict the probability of LISA-S. In our model, the core temperature at the time of NICU admission showed strong positive correlation with LISA-S (OR: 3.56 ; $95 \%$ CI 1.715 to 7.394$)$. Elevated CRP level (>10mg/L, OR: $0.280 ; 95 \%$ CI 0.101 to 0.775 ) decreased the possibility of LISA success. Birth weight (OR: 1.003; 95\% CI 1.002 to 1.004 ) and maternal age (OR: $0.923 ; 95 \%$ CI 0.860 to 0.991 ) were also significant predictors. Of the postnatal variables the highest respiratory severity score $\left(\mathrm{RSS}=\mathrm{CPAP} \text { level in } \mathrm{cmH}_{2} \mathrm{O} \times \mathrm{FiO}_{2}\right)^{33}$ in the first hour (OR: 0.463, CI 0.232 to 0.925 ), the dose of poractant alfa $<200 \mathrm{mg} / \mathrm{kg}$ (OR: $0.254 ; 95 \%$ CI 0.108 to 0.597 ) were analyzed as independent risk factors. In our sample, neither an incomplete nor a full ANS course showed significant effect even at univariate level. To demonstrate the predictive power of our model, we created a ROC curve using the predictive probabilities from the multivariate forward stepwise logistic regression model and the area under the ROC curve was 0.85 (E-image 1 ).

62 patients $(39.2 \%)$ received a second dose of surfactant, 31 via endotracheal tube and 31 with LISA. Among the latter, further surfactant treatment and/or mechanical ventilation could be avoided (LISA-R) in 18 cases $(58 \%)$. In spite of the relatively low case number we tried to identify predictors for the successful repeat of LISA. We made a similiar logistic regression model as we detailed above using the appropriate risk factors. Interestingly, no one from the prenatal variables showed sinificant difference even at univariate level. In the multivariate logistic regression model, we could not identify significant predictors for the probability of the success of the LISA retreatment.

Table 4 provides a comparison of the mortality and morbidity indices of the two study groups. Preterm infants in the LISA-F group required significantly longer hospital care and had a higher incidence of adverse outcome indices except ROP. Due to the low number of events, we could not reach statistically reliable conclusions on PVL, NEC, or mortality.

\section{Discussion}

Although early CPAP with LISA are effective in the treatment of RDS, mechanical ventilation cannot be avoided in the first three days of life in a remarkable number of preterm infants treated with LISA; therefore, it is important to identify neonates who would benefit from LISA over other methods of surfactant treatment. One of the key factors of LISA success may be the technical quality of administration, since surfactant regurgitation is known to frequently occur during this intervention. Whether effective CPAP is maintained during laryngoscopy also remains controversial ${ }^{13,34}$. To date, only one study assessed the risk factors and outcomes of LISA ${ }^{24}$.

We studied 39 potential variables and identified 6 independent predictors of the success of a single LISA: birth weight, maternal age, core temperature at the time of admission, highest RSS during the first hour of life or at the time of LISA, dose of poractant alfa $(<200 \mathrm{mg} / \mathrm{kg})$ and CRP levels $(>10 \mathrm{mg} / \mathrm{L})$ at 24 hours of life. The predictive power of our model is clearly indicated by the 0.85 AUC value of the ROC curve created 
by using the identified factors. Using our predictive model, a theoretical population may be identified where mechanical ventilation and/or surfactant retreatment can be avoided with a single LISA.

Our retrospective study found a significant incidence of CPAP failure after LISA, which was nearly identical to what was observed in previous studies ${ }^{14,15,24}$. In our study $34.1 \%$ of the preterm infants treated with LISA eventually required mechanical ventilation in the first 72 hours (Janssen et al. 30\%). In line with the study of Janssen et al.investigating LISA failure and INSURE failure, LISA success rates increased gradually with increasing gestational age until gestational week $28^{24}$. At gestational weeks 24 and 25 , mechanical ventilation could be avoided in the first 72 hours in nearly $60 \%$ of the subpopulation of preterm infants, which is higher than the rate published by Janssen et al. At the same time, the need for mechanical ventilation in the first 72 hours in preterm infants born at 26 weeks of gestation was significantly higher than in those born at 24 to 25 weeks. The likely explanation for this lays in delivery room care: the smaller a preterm infant is, the higher the delivery room intubation rate occurs. In other words, preterm infants born at 24 to 25 weeks of gestation were included in the study only after some pre-selection.

Unlike the study of Janssen et al. , our study did not reveal any association between the outcome of LISA and antenatal steroid prophylaxis ${ }^{24}$. The underlying reason may be the high steroid prophylaxis rates in both the LISA-S and LISA-F groups.

During our study we also observed correlation between outcome of LISA and hypothermia ${ }^{24}$. Preterm infants are more prone to develop hypothermia; admission temperature is a strong predictor of both morbidity and mortality in every gestational age group ${ }^{35}$. Although the correlation between RDS and hypothermia is well known, their causal relationship is rather questionable due to the fact that low admission temperature may also be the result of poor general condition, complicated transition, or the resulting prolonged delivery room stabilization $^{36}$. Jensen et al. found that infants with hypothermia on admission faced a two-fold increased risk for severe RDS or death within the first three days of life, but after adjustment for the risk factors that preceded admission temperature, this association was attenuated and statistically insignificant ${ }^{37}$.

We found that the initial dose of surfactant had a significant effect on the outcome of LISA: poractant alfa dose less than $200 \mathrm{mg} / \mathrm{kg}$ is associated with higher risk of LISA-F. Multiple studies investigated the effect of the dose of poractant alfa and $<200 \mathrm{mg} / \mathrm{kg}$ found to be a risk factor for treatment failure not only with the traditional administration with endotracheal intubation but also with the thin catheter method ${ }^{13,24,38}$. Accurate doses of surfactant seems to be crucial because surfactant reflux is a well known side effect of LISA, moreover, de Luca et al. in their bench study reported that surfactant loss around two or three times higher using thin catheter technique comparing endotracheal tube administration ${ }^{13,39}$. Despite these findings and current recommendations, both underdosing and dose rounding to full vials seems to be a significant issue in European countries ${ }^{38}$.

In accordance with results published by Janssen et al. elevated CRP levels were in strong association with lower LISA-S rates, which is understandable since impaired surfactant response was reported in preterm infants with perinatal infection and inflammation ${ }^{24,40}$.

In our sample, surfactant retreatment rate was 39.1\%. Of the 31 patients who underwent a second LISA, 18 succeeded on CPAP which is lower than the data reported by Janssen et al. (58\% vs. $77 \%$ ). In our study we used higher $\mathrm{FiO}_{2}$ treshold ([?]0.4 vs. [?]0.3) for the indication of second LISA, which is a possible explanation for this observation ${ }^{24}$. In our study, probably due to the low sample size we could not identify any predictive factor of retreatment failure. Further adequately powered studies are needed to clarify both the retreatment $\mathrm{FiO}_{2}$ treshold and the prediction of retreatment failure.

Compared to those with treatment failure, more favorable mortality and morbidity indices (except ROP) were observed in preterm infants in the LISA-S group. Although our results imply that LISA failure and subsequent mechanical ventilation may significantly impair outcomes, our retrospective study cannot establish a causal relationship. Nonetheless, a successful LISA may predict of more favorable patient outcome. A prospective study would be needed to confirm this assumption. 
Our study has some limitations. First, it is a retrospective study. Second, although there were strict indications for delivery room intubation, subjective opinion of the care provider may have overwritten them in some cases, which in turn could have affected the composition of the study population. Third, although our guideline of surfactant administration also defined strict criteria for treatment indication, time and method, the attending neonatologist had the libery to override them in individual cases based on the condition of the preterm infant.

In conclusion, failure of LISA is a relatively frequent event in preterm infants born before 33 weeks of gestation and is associated with adverse outcomes. Birth weight, maternal age, core temperature at the time of admission, highest RSS during the first hour of life or at the time of LISA, dose of poractant alfa and level of CRP are independent predictors of outcome of LISA. The incidence of LISA failure may be reduced by paying close attention to hypothermia prevention during early stabilization. The elimination of underdosing and dose rounding from clinical practice and lower retreatment $\mathrm{FiO}_{2}$ treshold $(0.3$ instead of 0.4$)$ should be considered to achieve higher LISA-S rates and better outcomes.

\section{Acknowledgements}

The authors of this article acknowledge the contributions of all the other staff members of the Division of Neonatology of the Department of Pediatrics of the University of Debrecen.

\section{References}

1. Stoll BJ, Hansen NI, Bell EF, et al. Neonatal outcomes of extremely preterm infants from the NICHD Neonatal Research Network. Pediatrics. 2010;126(3):443-456.

2. Klingenberg C, Wheeler KI, McCallion N, Morley CJ, Davis PG. Volume-targeted versus pressure-limited ventilation in neonates. Cochrane Database Syst Rev. 2017;10:CD003666.

3. Bjorklund LJ, Ingimarsson J, Curstedt T, et al. Manual ventilation with a few large breaths at birth compromises the therapeutic effect of subsequent surfactant replacement in immature lambs. Pediatr Res. 1997;42(3):348-355.

4. Schmolzer GM, Kumar M, Pichler G, Aziz K, O'Reilly M, Cheung PY. Non-invasive versus invasive respiratory support in preterm infants at birth: systematic review and meta-analysis. BMJ. 2013;347:f5980.

5. Subramaniam P, Ho JJ, Davis PG. Prophylactic nasal continuous positive airway pressure for preventing morbidity and mortality in very preterm infants. Cochrane Database Syst Rev. 2016(6):CD001243.

6. Stoll BJ, Hansen NI, Bell EF, et al. Trends in Care Practices, Morbidity, and Mortality of Extremely Preterm Neonates, 1993-2012. JAMA. 2015;314(10):1039-1051.

7. Sweet DG, Carnielli V, Greisen G, et al. European Consensus Guidelines on the Management of Respiratory Distress Syndrome - 2019 Update. Neonatology.2019;115(4):432-450.

8. Dargaville PA, Aiyappan A, De Paoli AG, et al. Continuous positive airway pressure failure in preterm infants: incidence, predictors and consequences. Neonatology.2013;104(1):8-14.

9. Dargaville PA, Gerber A, Johansson S, et al. Incidence and Outcome of CPAP Failure in Preterm Infants.Pediatrics. 2016;138(1).

10. Kakkilaya V, Wagner S, Mangona KLM, et al. Early predictors of continuous positive airway pressure failure in preterm neonates. J Perinatol. 2019;39(8):1081-1088.

11. Verder H, Agertoft L, Albertsen P, et al. [Surfactant treatment of newborn infants with respiratory distress syndrome primarily treated with nasal continuous positive air pressure. A pilot study]. Ugeskr Laeger.1992;154(31):2136-2139.

12. Kribs A, Pillekamp F, Hunseler C, Vierzig A, Roth B. Early administration of surfactant in spontaneous breathing with nCPAP: feasibility and outcome in extremely premature infants (postmenstrual age $</=27$ 
weeks). Paediatr Anaesth. 2007;17(4):364-369.

13. Vento M, Bohlin K, Herting E, Roehr CC, Dargaville PA. Surfactant Administration via Thin Catheter: A Practical Guide. Neonatology. 2019;116(3):211-226.

14. Gopel W, Kribs A, Ziegler A, et al. Avoidance of mechanical ventilation by surfactant treatment of spontaneously breathing preterm infants (AMV): an open-label, randomised, controlled trial. Lancet. 2011;378(9803):1627-1634.

15. Kribs A, Roll C, Gopel W, et al. Nonintubated Surfactant Application vs Conventional Therapy in Extremely Preterm Infants: A Randomized Clinical Trial. JAMA Pediatr.2015;169(8):723-730.

16. Gopel W, Kribs A, Hartel C, et al. Less invasive surfactant administration is associated with improved pulmonary outcomes in spontaneously breathing preterm infants.Acta Paediatr. 2015;104(3):241-246.

17. Kanmaz HG, Erdeve O, Canpolat FE, Mutlu B, Dilmen U. Surfactant administration via thin catheter during spontaneous breathing: randomized controlled trial. Pediatrics.2013;131(2):e502-509.

18. Isayama T, Iwami H, McDonald S, Beyene J. Association of Noninvasive Ventilation Strategies With Mortality and Bronchopulmonary Dysplasia Among Preterm Infants: A Systematic Review and Meta-analysis. JAMA. 2016;316(6):611-624.

19. Rigo V, Lefebvre C, Broux I. Surfactant instillation in spontaneously breathing preterm infants: a systematic review and meta-analysis. Eur J Pediatr.2016;175(12):1933-1942.

20. Aldana-Aguirre JC, Pinto M, Featherstone RM, Kumar M. Less invasive surfactant administration versus intubation for surfactant delivery in preterm infants with respiratory distress syndrome: a systematic review and meta-analysis. Arch Dis Child Fetal Neonatal Ed. 2017;102(1):F17-F23.

21. Wu W, Shi Y, Li F, Wen Z, Liu H. Surfactant administration via a thin endotracheal catheter during spontaneous breathing in preterm infants. Pediatr Pulmonol.2017;52(6):844-854.

22. Herting E, Hartel C, Gopel W. Less invasive surfactant administration (LISA): chances and limitations.Arch Dis Child Fetal Neonatal Ed. 2019;104(6):F655-F659.

23. Herting E, Kribs A, Hartel C, et al. Two-year outcome data suggest that less invasive surfactant administration (LISA) is safe. Results from the follow-up of the randomized controlled AMV (avoid mechanical ventilation) study.Eur J Pediatr. 2020.

24. Janssen LC, Van Der Spil J, van Kaam AH, et al. Minimally invasive surfactant therapy failure: risk factors and outcome. Arch Dis Child Fetal Neonatal Ed.2019;104(6):F636-F642.

25. Az Emberi Erőforrások Minisztériuma szakmai irányelve a koraszülöttek korai stabilizálása és a respirációs distressz-szindróma kezeléséról 2017. EüK. 20. szám EMMI szakmai irányelv. In. Vol LXVI. ÉVFOLYAM: Egészségügyi Közlöny:3624-3642.

26. Sweet DG, Carnielli V, Greisen G, et al. European Consensus Guidelines on the Management of Respiratory Distress Syndrome - 2016 Update. Neonatology.2017;111(2):107-125.

27. Silverman WA, Andersen DH. A controlled clinical trial of effects of water mist on obstructive respiratory signs, death rate and necropsy findings among premature infants. Pediatrics. 1956;17(1):1-10.

28. Jobe AH, Bancalari E. Bronchopulmonary dysplasia. American journal of respiratory and critical care medicine. 2001;163(7):1723-1729.

29. Rademaker KJ, Groenendaal F, van Bel F, de Vries LS, Uiterwaal CS. The DART study of low-dose dexamethasone therapy. Pediatrics. 2007;120(3):689-690; author reply 690-681.

30. Papile LA, Burstein J, Burstein R, Koffler H. Incidence and evolution of subependymal and intraventricular hemorrhage: a study of infants with birth weights less than 1,500 gm. J Pediatr. 1978;92(4):529-534. 
31. de Vries LS, Eken P, Dubowitz LM. The spectrum of leukomalacia using cranial ultrasound. Behavioural brain research. 1992;49(1):1-6.

32. International Committee for the Classification of Retinopathy of P. The International Classification of Retinopathy of Prematurity revisited. Archives of ophthalmology.2005;123(7):991-999.

33. Iyer NP, Mhanna MJ. Non-invasively derived respiratory severity score and oxygenation index in ventilated newborn infants. Pediatr Pulmonol.2013;48(4):364-369.

34. De Luca D, Shankar-Aguilera S, Centorrino R, Fortas F, Yousef N, Carnielli VP. Less invasive surfactant administration: a word of caution. Lancet Child Adolesc Health.2020;4(4):331-340.

35. Lyu Y, Shah PS, Ye XY, et al. Association between admission temperature and mortality and major morbidity in preterm infants born at fewer than 33 weeks' gestation.JAMA Pediatr. 2015;169(4):e150277.

36. McCall EM, Alderdice F, Halliday HL, Vohra S, Johnston L. Interventions to prevent hypothermia at birth in preterm and/or low birth weight infants. Cochrane Database Syst Rev. 2018;2:CD004210.

37. Jensen CF, Ebbesen F, Petersen JP, Sellmer A, Bach CC, Henriksen TB. Hypothermia at neonatal intensive care unit admission was not associated with respiratory disease or death in very preterm infants. Acta Paediatr. 2017;106(12):1934-1939.

38. Krolak-Olejnik B, Hozejowski R, Szczapa T. Dose Effect of Poractant Alfa in Neonatal RDS: Analysis of Combined Data from Three Prospective Studies. Frontiers in pediatrics. 2020;8:603716.

39. De Luca D, Minucci A, Gentile L, Capoluongo ED. Surfactant inadvertent loss using feeding catheters or endotracheal tubes. American journal of perinatology.2014;31(3):209-212.

40. Jackson CM, Mukherjee S, Wilburn AN, et al. Pulmonary Consequences of Prenatal Inflammatory Exposures: Clinical Perspective and Review of Basic Immunological Mechanisms. Frontiers in immunology. 2020;11:1285.

\section{Hosted file}

Image legends.docx available at https://authorea.com/users/436737/articles/538849-incidencepredictors-of-success-and-outcome-of-lisa-in-very-preterm-infants

\section{Hosted file}

Tables.docx available at https://authorea.com/users/436737/articles/538849-incidencepredictors-of-success-and-outcome-of-lisa-in-very-preterm-infants 
figures/Image-1/Image-1-eps-converted-to.pdf

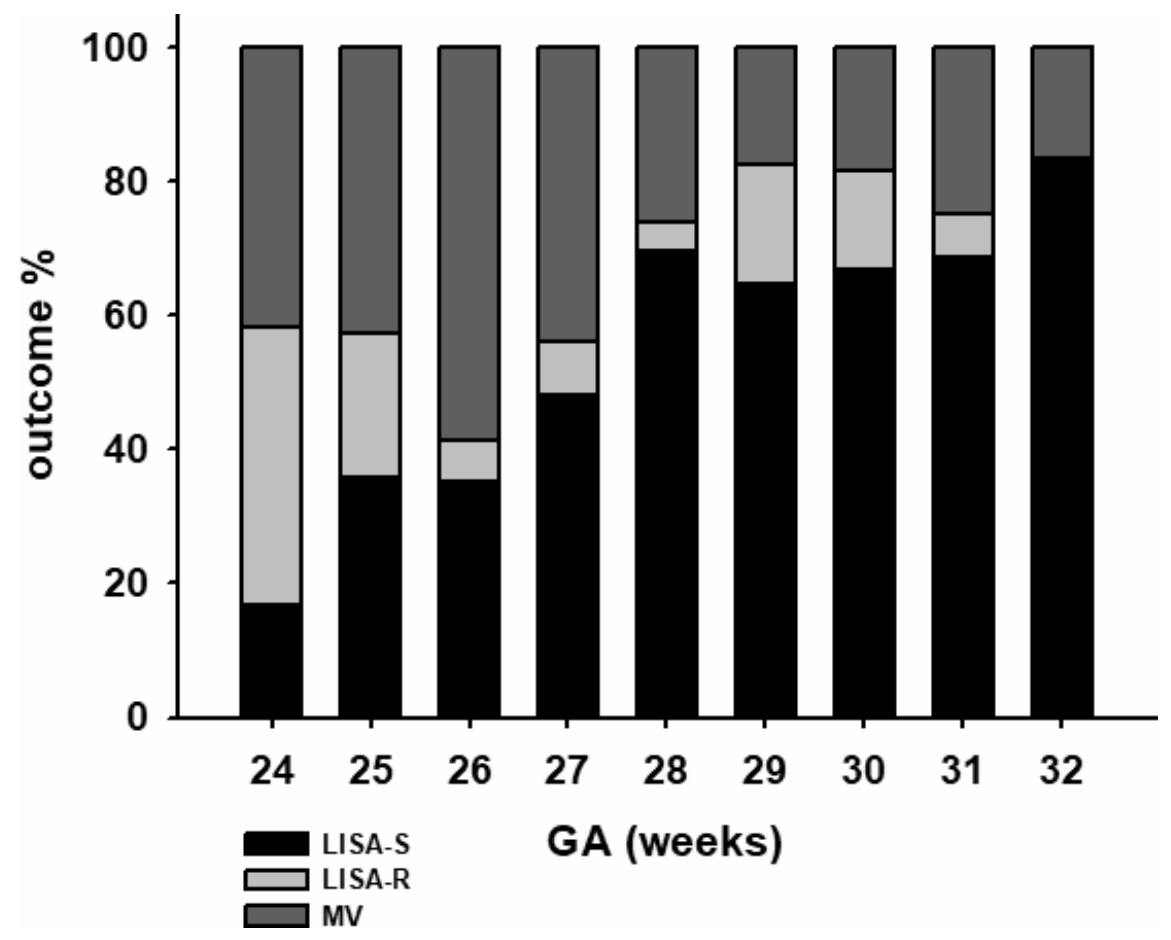

